\title{
LOS ROSTROS SILENCIADOS DE LA RESPONSABILIDAD
}

\author{
Cristina de la Cruz Ayuso \\ Aula de Ética de la Universidad de Deusto
}

\begin{abstract}
Resumen: Este artículo ofrece una lectura ética de la responsabilidad, aplicada a las organizaciones de la esfera económica de nuestras sociedades. Teniendo como marco de referencia la actual situación de crisis y las medidas que se están planteando de manera general para hacerla frente, en este trabajo se cuestiona críticamente el protagonismo otorgado a la responsabilidad en ese escenario y subraya las debilidades de su vertiente hegemónica. A partir de aquí, el texto recoge una llamada a rescatar otros rostros de la responsabilidad que tienen mayor entidad ética y exigen mayor densidad política, y propone recuperar el valor edificante de la responsabilidad, que llama y nos obliga a todos a cuidar la sociedad que todos componemos. La eficacia o adecuación de las distintas políticas, estrategias y herramientas para la promoción de la responsabilidad social deben responder a los retos que este valor edificante de la responsabilidad propone.
\end{abstract}

Palabras clave: Ética aplicada, responsabilidad, consecuencias, deber, transformación social.

\section{Resumo: Os rostros silenciados da responsabilidade}

Este artigo ofrece unha lectura ética da responsabilidade aplicada ás organizacións da esfera económica das nosas sociedades. Tendo como marco de referencia a actual situación de crise e as medidas que se están a formular de xeito xeral para facerlle fronte, neste traballo cuestiónase criticamente o protagonismo outorgado á responsabilidade neste escenario e subliña as debilidades da súa vertente hexemónica.

A partir de aquí, recóllese unha chamada ao rescate doutros rostros da responsabilidade que teñen maior entidade ética e esixen unha maior densidade política, e proponse recuperar o valor edificante da responsabilidade, que chama e que nos obriga a todas as persoas a coidar a sociedade que compoñemos. A eficacia ou a adecuación das distintas políticas, estratexias e ferramentas para a promoción da responsabilidade social deben responder aos retos que este valor edificante da responsabilidade implica.

Palabras clave: ética aplicada, responsabilidade, consecuencias, deber, transformación social.

\section{Abstract: The silenced faces of responsibility.}

This article offers an ethical reading of responsibility applied to organisations in the economic sphere of our societies. Having the current crisis situation and the measures which are generally being put forward to confront it as its frame of reference, this work critically questions the protagonism given to responsibility in that scenario and underlines the weaknesses of its hegemony. From here, the text includes a call to rescue other aspects of responsibility which 
are more ethical and demand greater political density, and proposes recovering the edifying value of responsibility, which calls and obliges everybody to take care of the society we are part of. The effectiveness or suitability of the different policies, strategies and tools for promoting social responsibility must respond to the challenges that the edifying value of responsibility proposes.

Key words: Applied ethics, responsibility, consequences, duty, social transformation.

\section{LA RESPONSABILIDAD SE DICE “DE MUCHAS MANERAS”.}

\subsection{LA DÉCADA DORADA DE LA RESPONSABILIDAD}

Nuestros retos pueden ser nuevos. Los instrumentos con los que los afrontamos pueden ser nuevos. Pero los valores de los que depende nuestro éxito (..) son algo viejo. Son cosas reales. Han sido el callado motor de nuestro progreso a lo largo de la historia. Por eso, lo que se necesita es volver a estas verdades. Lo que se nos exige ahora es una nueva era de responsabilidad (...). Este es el precio y la promesa de la ciudadanía. Ésta es la fuente de nuestra confianza. ${ }^{2}$

Estas palabras pertenecen a Barack Obama. Fueron pronunciadas durante la ceremonia de su toma de posesión a la presidencia de Estados Unidos en enero de 2009. La llamada a la responsabilidad con la que concluye el párrafo que extractamos es una más de las muchas que aparecen en el texto de su discurso inaugural. Obama apelaba entonces de manera reiterada a la necesidad de asumir con seriedad la responsabilidad para afrontar los grandes e ineludibles retos (y crisis) a los que se enfrenta no solo su país, sino el mundo entero. Sin embargo, esta obstinada referencia no era lo único que resaltaba en aquellas palabras pronunciadas para la "posteridad". Hubiese sido fácil (y pertinente) tachar de retórica esta insistencia de Obama si no hubiese incorporado en su discurso algún elemento más explícito sobre el estímulo que en algunos momentos requiere el "test de la responsabilidad". Y como siempre, tampoco entonces Obama defraudó. Es más, en aquel discurso prefiguró algunas de las que, más tarde, se han convertido en claves de su gestión (en el ámbito económico, al menos) en sus primeros cien días de gobierno: más control en el sector privado, más regulación de las instituciones, más intervención del Estado, más inversión publica, más deducciones fiscales, más vigilancia, más límites. El objetivo del plan Obama en el ámbito de la economía de mercado consiste, como primera medida de freno, en evitar la quiebra del sistema y acudir al rescate de sus principales pilares para sacarlos a flote. La mirada, en cualquier caso, y nuevamente en palabras de Obama, está puesta en el futuro: intentar hacer un país más justo y con una distribución más equilibrada de la riqueza. El mundo espera está vez los "efectos colaterales" de este plan de la administración Obama. Algunos lugares de ese "mundo" no pueden esperar mucho más a que se hagan efectivos también en sus propias realidades.

2 Extracto del discurso inaugural pronunciado por Barack Obama en la ceremonia de toma de posesión en enero de 2009, en ELPAÍS.com - Washington - 20/01/2009. [www.elpais.com]. Todas las referencias electrónicas de este artículo han sido comprobadas con fecha de abril de 2009. 
La exigencia de la responsabilidad, en este plan de Obama, va acompañada de otras medidas que buscan legitimarla y gestionarla. No basta únicamente con ser responsable. Es necesario también rendir cuentas a la sociedad de los resultados que tiene el ejercicio de la responsabilidad. Esta rendición de cuentas, con las consiguientes restricciones previas que esto implica, será de obligado cumplimiento para quienes además reciben ayudas del Estado. Las cinco referencias en su discurso inaugural a esta obligación (accountability) albergan la pretensión de evitar que se tilde de "pura retórica" esa llamada a la responsabilidad que Obama lanzaba al pueblo americano, seguro como estaba que era una llamada que llegaba además a muchos otros oídos del resto del mundo. Aquellas palabras recogían una declaración contundente sobre a quién corresponde gestionar la responsabilidad en la esfera publica en estos momentos, y sobre cómo hacerlo. El Estado ha adquirido un protagonismo extraordinario en el mercado y nunca como hasta ahora la actuación de los poderes públicos ha estado tan cerca de las empresas mercantiles para regular y limitar algunos aspectos de sus políticas empresariales. Sin duda, habrá que esperar para ver los resultados de esa invocación a la responsabilidad que el mundo ha recibido con una expectación contenida. La semilla parecer estar sembrada. Y sin embargo...

Quitándole la carga profética y el entusiasmo que suele acompañar a este tipo de declaraciones, la receta no aporta en cualquier caso muchas novedades. No parecen ser tiempos para innovar en política, ni siquiera para Obama. Los tiempos aconsejan volver a esas viejas cosas reales que en algún momento de la historia del progreso nos hemos empeñado en dejar en la cuneta. La responsabilidad parece ser una de ellas. Y por eso, en un escenario cuya cartografía está marcada por las huellas que ha dejado su falta, apelar a la responsabilidad quizás, ciertamente, no sea lo más alentador que cabe esperar de uno de los lideres políticos que más expectación ha levantado en estos últimos tiempos. Pero sí que es algo que, sin duda, ni siquiera un personaje como Obama Barack puede dejar de reclamar con la insistencia y contundencia con la que lo hizo en Washington.

En este caso, además, se hace desde el corazón mismo de una explosión no controlada, con efectos y consecuencias a escala mundial, cuya magnitud es difícil de predecir. Por eso, esa llamada guarda una sabia mezcla de intuición y sensatez ante los ojos del mundo: ¿cómo no apelar a la responsabilidad en un momento histórico tan crucial y en las circunstancias políticas, sociales y económicas en la que estaba teniendo lugar? Las crónicas previas al día de la investidura anunciaban el peso fundamental que tendría la responsabilidad en el discurso del presidente. Las crónicas del día después insistieron más en la esperanza. Y la valoración tras sus primeros cien días en el gobierno, insiste en la ilusión que despierta una propuesta de regeneración a la que todavía no le hacen sombra ni las sospechas ni las críticas. Una sabia mezcla ésta también, responsabilidad y esperanza, para mantener vivo el aliento ciudadano. Y en cualquier caso, un ejercicio de responsabilidad en sí mismo. Esperanza: sí. Responsabilidad también: sobre todo. Si no, el sueño americano se puede romper.

Sin duda, no queda más remedio que seguir insistiendo en la necesidad de la responsabilidad. Incluso con la insistencia con la que Obama lo escenificó ante el mundo 
entero el pasado mes de enero. Sin duda. No podemos prescindir de ella, aunque tiempos como los actuales le otorguen un protagonismo mediático que no sabemos muy bien cómo acoger y un frenético activismo que quiere dar una respuesta ágil, inmediata y efectiva a cada uno de los frentes que día a día abre la crisis económica a nivel mundial.

Pero también es cierto, como decimos, que es una demanda que aporta poca novedad. Y que causa también perplejidad ante la desmedida confianza que ahora parece recaer sobre ella como parte del remedio a los males que nos acucian. ¿Se trata entonces de "responsabilidad"? Si es así: la cosa no parece, sobre el papel, tan complicada. Pero, quizás precisamente por eso, porque se trata tan solo de responsabilidad, la cosa no sea tan fácil como parece a primera vista.

De hecho, no es la primera vez que, quizás no con tanto alcance mediático pero sí con igual contundencia, se subraya a nivel mundial la necesidad de restaurar en la esfera pública (principalmente en el ámbito económico) el valor de la responsabilidad, advirtiendo sobre la no sostenibilidad del mercado si sus reglas siguen dándole la espalda.

"Les propongo que ustedes, los líderes empresariales reunidos en Davos, y nosotros, las Naciones Unidas, iniciemos un pacto mundial de principios y valores compartidos, que darán una cara humana al mercado global”.

Estas palabras pertenecen a Kofi Annan. Fueron pronunciadas en un discurso ante el Foro Económico Mundial de Davos en enero de 1999, con el objetivo de presentar una iniciativa mundial, el Global Compact ${ }^{3}$, que propone fomentar la responsabilidad cívica de las empresas para que éstas contribuyan a responder a los retos que plantea la globalización y ayuden a hacer realidad una economía mundial más sostenible e inclusiva. Esta iniciativa fue adoptada formalmente 18 meses después, en julio de 2000, en la Sede de las Naciones Unidas en Nueva York. Invitaba a colaborar a las empresas con los Organismos de las Naciones Unidas, las organizaciones laborales y la sociedad civil para promover, con un carácter universal, principios sociales y medioambientales que facilitasen a las empresas, principalmente a las compañías multinacionales, elementos para la gestión de su responsabilidad en un escenario de economía global, y claves para el seguimiento de dicha gestión por parte de los poderes públicos, la sociedad civil y la ciudadanía en general.

Entre las dos declaraciones, la de Obama y la de Kofi Annan, median exactamente diez años. La precisión resulta elocuente, teniendo en cuenta que el intervalo que queda atrapado entre 1999 y 2009 puede ser considerado con todo rigor la "década dorada de la responsabilidad”: el periodo en el que más esfuerzos se han hecho y más recursos se han destinado para que la responsabilidad eclosione en la esfera económica del mercado mundial. Y sin embargo la tozuda realidad, en un contexto de crisis económica como el actual, nos obliga a tener que concluir que esos esfuerzos han sido baldíos. Ni siquiera la responsabilidad parece haber sido suficiente para evitar la debacle económica. 
La mayor parte de las iniciativas de responsabilidad en el ámbito empresarial esta última década, se han centrado principalmente en cuestiones similares a las que ahora reclama Obama: control, buen gobierno, transparencia, rendición de cuentas, límites y sistemas de vigilancia en algunos sectores, consorcios, alianzas, partenariados, etc. La actividad ha sido escandalosamente frenética. Descontrolada incluso. Desproporcionada. Y poco eficaz, a la luz de los resultados.

Sin entrar a hacer una valoración exhaustiva, lo que sí cabe subrayar ahora es la necesidad de sacar alguna conclusión serena. Y es que quizás la formula de la responsabilidad no consiste únicamente en "más control + más límites + más vigilancia". Que esa sea una formula necesaria, no quiere decir que por ello sea una formula suficiente. De hecho, incluso cabe decir, en cierta manera, que es una formula fracasada. Por eso, resulta un poco inquietante que solo se planteen como respuesta las mismas medidas que se vienen articulando durante los últimos años, y que ya han mostrado su ineficacia y fragilidad para regular el mercado.

Obama ha recibido el apoyo moral y político de los lideres mundiales más poderosos para liderar una estrategia que permita hacer frente a esa pandemia económica con la que su país ha infectado a todo el planeta. Para ello, reclama responsabilidad. Y define una estrategia poniendo en marcha medidas que afectan a instituciones sobre las que ya pesaba desde hace años igual demanda. Los resquicios del mercado les permitieron a todas ellas, sobre todo a las empresas trasnacionales, sortear las exigencias de la responsabilidad, y nada apunta a que terminen llegando mejores tiempos mientras las reglas del mercado sigan siendo las mismas que las que han permitido a las empresas poder burlarse de la responsabilidad. Mientras esto sea así, el "sueño" de Obama de hacer un país más justo y con una distribución más equilibrada de la riqueza parece que tendrá que esperar. Y con él, el resto del mundo.

\subsection{LA DÉCADA FRACASADA DE LA RESPONSABILIDAD}

Quizás resulte excesivo adjetivar de "fracasada" esta ultima década en la que tan espectacular protagonismo ha tenido la responsabilidad. Si hemos acudido a un marco tan actual como el firme compromiso por la responsabilidad asumido por Obama, es precisamente para remarcar, a través de ese ejemplo tan cercano, las contradicciones a las que se expone de manera reiterada en la esfera pública a un valor tan imprescindible como parece ser la responsabilidad. En este caso, la contradicción se tiñe además de cierta perplejidad cuando vemos que las propuestas que nos ofrece se sustentan en estrategias que han dado muestras evidentes de debilidad ante las recias reglas del mercado, y apelan, en última instancia, al esfuerzo personal y a la conciencia individual para asumir con coraje y valor el porcentaje de responsabilidad que nos corresponde a cada cual en ese escenario; como si esas épicas llamadas a la responsabilidad individual fuesen suficientes para hacer frente a las consecuencias a nivel global de la actual crisis económica.

Nuestras sociedades necesitan ciudadanos responsables. Sin lugar a dudas. Pero necesitan igualmente de instituciones que propicien el ejercicio de la responsabilidad. Necesitan también de instituciones justas. Y responsables. Instituciones que sean capa- 
ces de plantear alternativas diferentes a la hegemonía de las reglas del mercado. Mientras esta base del sistema no se alteré, de poco sirve exigir y esperar responsabilidad de la ciudadanía en un contexto que alimenta todas las condiciones para que no lo sea; para que la ciudadanía renuncie a la responsabilidad. Y, lo que es peor: para que, al igual que esas instituciones, la ciudadanía también pueda sentirse indefectiblemente inocente ante las consecuencias que tiene la dilución de cualquier tipo de responsabilidad en la esfera publica: ya sea ésta individual o institucional.

La responsabilidad es un valor que sufre una dolorosa esquizofrenia: por un lado, es un valor al que nadie puede renunciar. ¿Acaso cabe ensalzar como una cualidad la falta de responsabilidad? ¿Es posible encontrar a alguien dispuesto a declarar que es un valor del que se puede prescindir? Y sin embargo, por otro lado, la responsabilidad es uno de esos principios éticos que mayores desaires recibe a todos los niveles.

La responsabilidad además es un valor que sufre las dolorosas consecuencias de su falsa polisemia. No remite a significados distintos. Sin embargo, es un término al que se le asignan contenidos que tienen que ver, en cierta manera, con su sentido primigenio pero que, por distintas razones contextuales, terminan por desvirtuarlo y por forzar su complejidad conceptual. De hecho, uno de los argumentos más repetidos a lo largo de esta última década apunta a la dificultad para concretar qué es la responsabilidad y cuál es su alcance en la esfera pública. El debate en torno al concepto, durante esta última década, ha sido tan intenso como estéril. A día de hoy, el esfuerzo por concretar su significado todavía no ha conseguido contundente unanimidad. Ni siquiera amplios consensos. Lo cual arroja una carga de sospecha inevitable ante esas dificultades. ¿No será acaso que se vive mejor desconociendo su significado?

El debate, lamentablemente, ha quedado reducido a una respuesta unánime, que no deja de resultar paradójica. Y, en cualquier caso, es decepcionante: la responsabilidad se dice de muchas maneras. $\mathrm{O}$ eso parece. Tantas, que quizás no merezca la pena atraparla definitivamente en una recia y roma definición que no dé cuenta de su riqueza y potencial. Eso se dice. Y se argumenta de la siguiente manera: la responsabilidad remite a contenidos distintos en la esfera económica y no cabe generalizarla bajo unas mismas siglas (RSE) para referirse por igual a la responsabilidad, por ejemplo, de las entidades financieras que a la responsabilidad de las empresas del sector turístico. Los objetivos y estrategias empresariales son distintos en uno y otro caso, los grupos de interés también; y por tanto la exigencia de responsabilidad se tendrá que concretar igualmente de acuerdo a las particularidades de unas y otras respectivamente. Dejémonos, por tanto, de sutilizas conceptuales y centrémonos en lo fundamental: en su valor edificante, en su rehabilitación en las instituciones y entidades, publicas y privadas, de la esfera económica. No se trata de alcanzar un concepto adecuado y definitivo de la responsabilidad, sino de que realmente nos volvamos todos un poco más responsables. Ese ha sido el mensaje que se ha ido forjando esta ultima década. El problema es que, a día de hoy, no solo no hemos conseguido serlo. Basta con remitirse a los hechos. Sino que carecemos también de un concepto adecuado de responsabilidad que nos permita albergar la esperanza de que sea posible serlo en una economía del mercado como la actual. 
El argumento de la "practicidad" ha ganado la batalla a las ideas. Y las consecuencias de este dinamismo, como decimos, ha abonado las coartadas para aplazar su realización efectiva en la esfera publica: a algunos, este afán práctico les ha servido para ponerse manos a la obra, sin poder situar sus esfuerzos en una acción colectiva, conjunta y coordinada, impidiendo de esta manera que la "practica" de la responsabilidad vaya teniendo una acción significativa en la esfera económica. A la mayoría, la llamada a la responsabilidad les ha dejado fríos, a falta de una aclaración que justifique su necesidad, de ahí que haya sido posible "prorrogar" su ejercicio e incluso programar su puesta en marcha, haciéndola coincidir con un momento más propicio de la estrategia empresarial. Y a otros, en fin, todo esto les ha servido para estar alertas y valorar la conveniencia o no de sumarse a esta "nueva" ola de gestión empresarial a tenor de los resultados obtenidos por quienes tomaron la iniciativa o por el rumbo que cada cuatro años va tomando el pulso de los poderes públicos sobre estos temas.

Las coartadas, en fin, son infinitas. Agotadoras. Destacan algunas por su "virtuosismo":

- La de los reticentes: aquellos que se resisten con desaire a los procesos de verificación y de vigilancia que a veces exige el compromiso con la responsabilidad. Ante el temor de una posible contaminación "socialista" en el ámbito de las empresas privadas, arguyen con contundencia que estos procesos de responsabilidad alejan o dificultan el logro de otras metas, más legítimas, del proyecto empresarial. Entre ellas, las relacionadas con la maximización de los beneficios.

- La de los afectados: aquellos que responden airados cuando no ven más que sospecha, recelo o falta de confianza a la demanda de explicitar el compromiso por la responsabilidad con otras formulas distintas, que vayan más allá de una simple declaración de principios institucional. ¿Pero es que acaso la responsabilidad exige algo más que un compromiso?

- La de los colaboracionistas: aquellos que, simplemente, viven mejor ignorando parte de la realidad. Levantando los hombros ante las desigualdades, y arqueando las cejas ante la posible "carga" que a cada uno pueda tocarle. Es mejor no saber qué es la responsabilidad. Es mejor rechazar cualquier intento de desvelar sus distintos rostros y el alcance que tiene. Ese "saber" no te permite ser inocente. Provoca inquietud, trae problemas, dispersa poder, genera gastos. Es molesto, e incomodo.

La responsabilidad, en definitiva, parece ser demasiado pedir, al menos en el ámbito económico y empresarial.... Demasiado pedir. ¿Cómo se alivian estas idas y venidas a través de la cartografía de la responsabilidad? Pues a veces con un activismo desenfrenado, o con hipocresía; otras con cinismo, otras con remordimiento. Otras con ironía. Y otras, simplemente, levantando los hombros. $\mathrm{O}$ arqueando las cejas. $\mathrm{O}$ cerrando los ojos. O cruzando los dedos.

La responsabilidad, desde su dimensión práctica y en la esfera económica, ha estado siempre asociada a la cuestión de los "beneficios", y de alguna manera se ha llegado a justificar la inevitabilidad de dicha asociación en el ámbito empresarial. A fin de cuen- 
tas, si a las empresas se les pide el esfuerzo de ser responsables y eso implica destinar recursos para ello, ¿cómo no acoger con buenos ojos que, al menos, eso les reporte algún beneficio concreto: económico, de imagen, de consolidación de marca, de posición en el mercado, etc.? ¿Es legítimo que, a propósito de la responsabilidad, la empresa tenga expectativas de que esto le reporte algún beneficio concreto? Si bien sobre el concepto ha sido imposible alcanzar unanimidad, respecto al argumento comercial de la responsabilidad no ha habido dudas. Por supuesto.

La quiebra y el rápido declive del debate sobre las ideas, que así es como se le ha llamado al intento de delimitar el significado de la responsabilidad en la esfera económica, cedió con cierta celeridad a los reclamos de quienes proponían pasar con audacia de la teoría a la acción, exigiendo criterios y herramientas para su aplicación. Y recursos y apoyos de la administración. Lo que queda de aquel debate de ideas de principios de siglo XXI es una aproximación ambigua al concepto de la responsabilidad, lo suficientemente imprecisa como para que resulte políticamente correcta y permita acallar, con aplomo y poder, esos otros rostros silenciados de la responsabilidad que han quedado atrapados en cotos deliberadamente vedados. El resto de la aventura de la responsabilidad esta última década la resume una imparable, frenética y abrumadora carrera por generar complejos sistemas de medición del impacto de la actividad empresarial, un intento [frustrado] de organizar una agenda que permita transversalizar el enfoque de la responsabilidad en las políticas públicas económicas y sociales, y una torpe y desigual respuesta del ámbito empresarial: la buena voluntad de algunos se ha visto ensombrecida por las coartadas y las excusas de la mayoría.

El discurso políticamente correcto sobre la RSE ha terminado convirtiendo a la responsabilidad en una realidad virtual: la responsabilidad se ha convertido en una herramienta de gestión que nos permite cuantificarla y ordenar los datos en aplicaciones informáticas que te devuelven complejos informes o memorias de resultados estándar, ya elaboradas y dispuestas para ser presentadas en sociedad. Todo esto, por supuesto, avalado por organizaciones que han convertido a la RSE en uno de los nichos de negocio más productivo de esta última década. Un nicho de mercado abrumador, al que no le faltan webs especializadas que compiten entre ellas por ocupar los primeros puestos de un ranking que cuantifica cuál es la más visitada.

El fin -recordémoslo- era convertir la responsabilidad en algo edificante: llegar a ser más responsables. Este ha sido el ensayo que se ha intentado alcanzar esta última década. El resultado es que la responsabilidad en la esfera económica no ha sido más que un medio: un propósito para otra cosa. La explosión de la crisis y las palabras de Obama marcan el cierre de una etapa, con una conclusiones sobre las que no hace falta seguir insistiendo. Y sin embargo....

\subsection{REVISAR EL SENTIDO DE LAS PALABRAS ES UNA LABOR INELUDIBLE}

No tenemos por qué renunciar a esa responsabilidad virtual. Aun reconociendo su insuficiencia e incluso sus limitaciones, nos ofrece una lección que no podemos desechar. Las críticas a la responsabilidad, tal y como se ha ido articulando esta ultima déca- 
da, no deben convertirse en una oportunidad para claudicar definitivamente de ella. Conviene, por el contrario, aclarar los pilares sobre los que se sostiene, y tratar de poner de manifiesto las limitaciones que tiene la dirección a la que apuntan las respuestas que se están dando desde esas coordenadas, y que poco tienen que ver con otros rostros más reales de la responsabilidad.

Esa vertiente de la responsabilidad, que la sitúa con más propiedad en el ámbito de la ingeniería que de la ética, nos muestra una lección sobre la necesidad de revisar el sentido de algunas palabras. Es una vertiente de la responsabilidad de la que no debemos prescindir al menos por varias razones:

- Es una vertiente que subraya y valora algunos esfuerzos realizados en el entramado empresarial, y también pone de manifiesto su fragilidad. Son esfuerzos que solo se visibilizan en tiempos de bonanza económica. Si los vientos económicos no soplan a favor, su rastro desaparece.

- Es una vertiente que pone de manifiesto las expectativas que la ingeniera de la responsabilidad genera en la esfera económica, y la manera en la que se articula en torno a otros objetivos distintos que, a veces, nada tienen que ver con la responsabilidad misma.

- Es una vertiente que ofrece elementos para comprender los yugos inevitables a los que está sometida. Son precisamente estos yugos los que han ido conformando el surco de su trayectoria estos últimos años.

- Es una vertiente que pone en evidencia, por mucho que se intente acallar este alcance, las estructuras de poder excluyentes sobre las que se sustenta; las circunstancias excluyentes que la alimentan, y los agentes que ostentan el poder en la esfera del mercado para tomar decisiones colectivas que nos afectan a todos.

- Es una vertiente, en definitiva, que nos brinda argumentos suficientes para confirmar que no conviene dejar cautivo el sentido de la responsabilidad en esos estrechos límites y bajo esas condiciones.

- Es una vertiente, en fin, que apunta a la necesidad de abrir otras vías de reflexión y de práctica de la responsabilidad, cuya senda conviene seguir bajo la guía que nos ofrecen esos otros rostros silenciados por la versión hegemónica de la responsabilidad.

Estos otros son rostros que atesoran distintos matices de la responsabilidad. La importancia de rescatarlos no se sustenta únicamente en la urgencia de completar las insuficiencias que denota su lectura oficial. Su importancia está en que al recatarlos, les conferimos entidad ética y densidad política. Los nombramos. Y al nombrarlos, desplegamos su sentido, y con él, todo su potencial. Los igualamos con la versión hegemónica y mostramos, a partir de ellos, lo que nos es posible. Nombrar esos rostros permite crear un espacio que les otorga en la esfera publica poder y legitimidad. Son rostros que no buscan el valor edificante de la responsabilidad, pero, sin embargo, lo facilitan. De él se sirven para hacer algunas transiciones en nuestras sociedades orientadas a la progresiva transformación de algunas estructuras excluyentes en nuestra economía del mercado. 


\section{EL ROSTRO HEGEMÓNICO DE LA RESPONSABILIDAD Y SUS INSUFI- CIENCIAS.}

Empecemos, por tanto, desenmascarando la versión hegemónica de la responsabilidad en la esfera económica. La que ha construido su rostro en torno a la arquitectura de las consecuencias, haciendo incidencia principalmente en el impacto (social, económico y medioambiental) de la actividad empresarial. La construcción de la responsabilidad desde este enfoque de las consecuencias podemos articularla en torno a la metáfora de las ondas expansivas que produce un objeto cuando es arrojado a una laguna. Ese es un efecto imprevisto, aislado, repentino, cuya magnitud depende del tamaño del objeto arrojado y de la fuerza que lo acompaña hasta rozar con la superficie líquida. Visto desde lejos, la laguna permanece en calma hasta que se ve alterada por los efectos que un objeto extraño provoca en ella al ser lanzado con más o menos intensidad. Esta representación de la responsabilidad nos sirve para indicar la metáfora que sugieren las consecuencias que la actividad empresarial tiene inevitablemente en la sociedad, pero enfatiza el carácter extraño que, en ese contexto, se otorga al sujeto que las provoca.

Pues bien, esta extrañeza es la que siempre acompaña a ese enfoque de las consecuencias cuando se pretende explicar el rostro edificante que debiera tener la responsabilidad, en vez de ese otro defensivo, que es el que mayoritariamente genera en la esfera económica. Una vez arrojada la piedra, casi todos los que concurren en esa esfera se afanan por esconder la mano, y mostrar cierto desaire cuando se les pide que expliquen si ellos tienen que ver con esas ondas expansivas que han roto la calma de las aguas de la laguna. Hay quien argumenta, para tratar de demostrar que nada les vincula con el objeto "caído", que quizás su encuentro es fortuito; que quizás sea producto incluso del azar. O quizás de condiciones que no dependen de nadie sino que ocurren de manera extraordinaria e imprevisible y que, quizás, ni siquiera se pueden evitar. Las ondas pueden ser consecuencia sin más de un desprendimiento provocado por el deshielo. O son una respuesta a los juegos de los excursionistas que visitan la laguna. Son un grupo tan numeroso que resulta imposible saber quién de todos ellos ha provocado ese efecto en el agua. Quizás realmente hayan sido todos ellos a la vez debido a su presencia ingobernable en la laguna. Siempre hay argumentos para hacer valer la inocencia de lo que ocurre.... incluso la de de quien está allí esperando a que, tras una amena tarde de pesca, algo pique en el anzuelo. ¿Las ondas? Pues probablemente, consecuencia del peso de la plomada que hemos puesto en el anzuelo. Tampoco es para alarmarse.

Podemos tentar esa metáfora de las ondas expansivas hasta donde queramos. En la práctica $^{4}$, el ejercicio de la responsabilidad responde en buena medida a lo que ella repre-

4 Un desarrollo pormenorizado del alcance de este enfoque de la responsabilidad basado en las consecuencias ha sido desarrollado también en Cruz, C.; Sasia, P. y Guibert, J.M. (2007): "La responsabilidad social en Gipuzkoa ¿por dónde empezar?”, en Guibert. J.M. (coord.) Empresa y Responsabilidad Social en Gipuzkoa. San Sebastián: Universidad de Deusto, pp. 23-40 y en Sasia, P.M. y de la Cruz, C. (2008): Banca ética y ciudadanía. Madrid: Trotta. En este apartado nos apoyamos de manera indirecta en estos trabajos. 
senta. La responsabilidad, desde el enfoque de las consecuencias, se atrapa en un débil argumento: hay una acción y una reacción a los efectos que aquella tiene en el contexto donde se produce. Desde este esquema, es fácil identificar al actor de la acción, y por tanto al sujeto a quien corresponde asumir las consecuencias, el impacto positivo o negativo que se deriva de las mismas. Pero, sin embargo, el curso de las acciones no es siempre tan sencillo y por tanto no todo está bajo control cuando de asumir responsabilidades se trata. Las estaciones intermedias en esa secuencia acción-reacción ponen de manifiesto lo mucho que esa secuencia se complejiza en el marco de las organizaciones donde se producen efectos no pretendidos, riesgos futuros que no se pueden controlar, o a los que es difícil asignar un responsable directo. A mayor complejidad e interdependencia en el proceso en el que se inscribe la actividad empresarial, mayor complejidad de los problemas, mayor impacto, mayores consecuencias, y consecuentemente menor control, menor capacidad para asignar responsabilidades y para dar una respuesta adecuada.

Esa actividad, además, tiene lugar en un escenario de economía de mercado global. En él, la exigencia de una responsabilidad basada únicamente en las consecuencias, en el impacto de la acción, es claramente insuficiente. El movimiento RSE pretende ser una respuesta a ese contexto global; una llamada a que las organizaciones se dispongan a asumir los retos que este escenario les plantea. El horizonte es tan amplio que parece resultar inabarcable para algunas empresas, principalmente para las pequeñas y medianas empresas. Y el escenario es tan inabordable en sí mismo que permite a otras que el rastro de su responsabilidad se pierda definitivamente entre las miles de autopistas que cruzan a su lado. La manera en la que la mayoría de las empresas están respondiendo a las demandas de responsabilidad en un contexto global, cuyo control se les escapa o cuya inmensidad les permite camuflarse en una red de alcance planetario, es autolimitando esas demandas de responsabilidada lo que a ellas, como empresas, les es posible y legítimo. Las empresas son únicamente responsables de aquello que ocurre dentro de su ámbito propio de actuación. Su función es ofrecer productos y servicios a la sociedad. Este es el marco de juego en el que se debe fijar su responsabilidad, condicionado a una cuestión que parece inevitable: "es una función que, en cualquier caso, está supeditada al objetivo de ganar dinero". El fin de la empresa, se dice, es ese y no otro; y las demandas de responsabilidad que excedan este marco deberán ser respondidas por el Estado, las ONGs o cada individuo en la medida que les corresponda. Pero no por la empresa ${ }^{5}$. No al menos única y exclusivamente.

Esta aparente resistencia de las organizaciones a la responsabilidad pocas veces se cuestiona. Menos en tiempos de ajuste económico como los actuales en los que la crisis

\footnotetext{
5 El economista americano y premio Nobel de Economía Milton Friedman afirmaba en varios textos entre 1966 y 1970 que la Responsabilidad Social de las empresas se debe limitar a cumplir las reglas básicas de la sociedad, encarnadas en la ley y en las costumbres morales. Defendía que las empresas no están legitimadas para decidir cuáles son las prioridades en términos de asistencia a colectivos necesitados, ya que esto supone arrebatar una capacidad únicamente atribuible a los poderes públicos democráticamente elegidos y sometidos a control. Por eso, acusaba a los directivos que deciden desviar fondos hacia este tipo de actividades de penalizar a los accionistas, poniéndoles unos nuevos impuestos.
} 
parece haber ganado la batalla a una RSE acallada por la tozudez de la realidad económica. Y todo lo que vaya más allá de ese argumento se convierte, de hecho, en ingeniería organizacional a nivel interno, y en filantropía o mecenazgo de puertas hacia afuera. Y sin embargo...

Hay poderosos matices que hacen que en el caso de las organizaciones empresariales todo esto que venimos diciendo respecto al enfoque consecuencialista de la responsabilidad no sea exactamente tal y como comúnmente se plantea. La metáfora de las ondas expansivas lo representa bien: las empresas, sobre todo los grandes grupos trasnacionales, son uno de los elementos claves de esas redes que complejizan los intercambios económicos. Tienen además un inmenso poder: las decisiones colectivas que estas organizaciones toman son capaces de configurar comunidades enteras. También son quienes traccionan a otras empresas más pequeñas, incluso a muchas administraciones y, por supuesto, a todos los consumidores posibles. Para el entramado de los grandes grupos empresariales escudarse en las estructuras, la ignorancia o la impotencia es inaceptable. Ellas son buena parte de esas estructuras. Ellas tienen el poder y el conocimiento. Tienen, por tanto, la capacidad de hacerse cargo. No son las víctimas, sino los creadores de estas complejas redes que la globalización ha traído. Por lo tanto, es legítimo preguntarse: ¿es ceguera inocente o inhibición consciente?

Todo apunta a que se trata, más bien, de "inhibición consciente": una estrategia que utilizan las empresas para delimitar los contornos de su responsabilidad. La ignorancia es una "herramienta" que justifica esa "inhibición". Las dificultades estructurales, son otra. Los elementos del entorno, otra... y así podemos proseguir ad infinitum. Pero son inhibiciones, en muchos casos, conscientes, y deliberadamente intencionadas: las empresas acuden con celeridad a su deber de ser económicamente rentables, de obtener beneficios, de crear riqueza y cuestiones similares. La necesidad de obtener beneficios económicos se convierte, de esta manera, en un "objetivo-llave" que condiciona a cualquier otro que pretenda alinearse con él. Incluido el de la responsabilidad. Y aquí es donde nos encontramos una de las barreras más difíciles de sortear en el ámbito empresarial. De hecho, en cualquier coloquio sobre RSE, tras una nube de propuestas, ejemplos de buenas prácticas, herramientas y metodologías, surge siempre inevitablemente el siguiente comentario: "de acuerdo, todo esto está muy bien, pero yo necesito seguir siendo económicamente rentable para pagar los sueldos, invertir, crecer, etc."

Esta línea de argumentación pone de relieve un dilema de muy difícil solución en los términos en los que está planteado: si los objetivos económicos forman parte esencial de la razón de ser de una organización, ¿cómo supeditarlos, o al menos equilibrarlos, con otros objetivos que son sospechosos de apuntar en una dirección completamente opuesta? ¿Cómo puede una empresa permitirse desarrollar líneas estratégicas que vayan en contra de la obtención de beneficios económicos? Como mucho, es posible desarrollar propuestas "responsables" que traten de mostrar su capacidad de consolidar, al menos a medio y largo plazo, buenos resultados económicos. Y esto último, claro está, siempre y cuando la empresa vaya bien y tenga buenos resultados. En momentos de ajuste, como hemos señalado, ni pensar en "acción social". El discurso de la responsabilidad 
social de la empresa se somete de esta forma a un yugo difícil de eludir, que condiciona toda propuesta de ampliar su responsabilidad bajo el dilema de mostrar su "utilidad".

Una manera de empezar a sortear estas dificultades, es aclarando algo que ya se sabe suficientemente pero sobre lo cual existe interés en que siga siendo algo confuso: cuando se reclama el derecho de un proyecto empresarial a ganar dinero, conviene distinguir para entender el alcance de este "derecho" que no es lo mismo perseguir la sostenibilidad económica de una entidad que situar la maximización del beneficio económico como objetivo primordial de su actividad. El carácter lucrativo de una entidad es un factor determinante para entender no solo la manera en la que articula su propia responsabilidad. También es un factor crucial para entender las dificultades que las organizaciones tienen para aplicar criterios de responsabilidad. En una organización lucrativa, toda su estrategia parece estar inevitablemente ligada a la maximización del resultado económico. En ellas, toda decisión y toda actuación orientada a responder más allá de la actividad propia, deberá inevitablemente pasar el "test de utilidad", que demuestre que esas decisiones o actuaciones son útiles para el resultado económico de la organización. Por lo tanto, una organización así solo asumirá responsabilidades si quienes tienen la capacidad de decisión perciben que puede haber algún tipo de rentabilidad económica.

El carácter lucrativo no es el único factor de bloqueo para el ejercicio de la responsabilidad. También lo es, fundamentalmente, el empeño por la instrumentalización de la responsabilidad. Efectivamente, el intento por homogeneizar enfoques de aplicación y estandarizar indicadores para su contrate y mejora en el marco empresarial ha provocado una desnaturalización de la responsabilidad y un alejamiento de las particularidades del tejido empresarial de un determinado territorio y su incidencia en el tejido económico y empresarial. Es difícil pensar que los armazones conceptuales y las directrices de aplicación puedan servir indistintamente para todos los contextos, al margen de las condiciones que configuran socio-económicamente ese entorno. Incluso las variables culturales y ambientales tienen una incidencia notable en la manera en la que se ha de adecuar el discurso RSE en cada contexto que no puede pasar desapercibida en sus intentos de aplicación práctica.

A veces causa pudor ver de qué manera en entornos diversos a los "europeos" se trata de replicar (y vender) el modelo surgido bajo su seno, cuando las claves de referencia, sociales y culturales, también económicas, son bien distintas en estos otros escenarios. No hace falta cruzar ningún océano para constatar la necesidad de adecuar el enfoque RSE a cada contexto: existen elementos del entorno que son incuestionables, que condicionan las políticas públicas de RSE, que marcan las directrices de las acciones estratégicas de las empresas en relación con su responsabilidad. Las demandas de RSE no son iguales en todos los contextos. Las necesidades a las que hay que atender tampoco son las mismas.... ¿cómo es posible entonces que, de manera mayoritaria, todas las empresas parezcan estar preocupadas por lo mismo cuando se les trae a colación el "asunto RSE"? No se trata de que todas reciclen papel, hagan un uso responsable de la energía, o inviten a ser responsables a los clientes con el uso del agua. No se trata solo de atender a ciertas demandas de la comunidad que despiertan la simpatía, el interés o la preocupación de las empresas. No se trata en realidad de responder "todos a una". 
La centralidad que han adquirido las ondas expansivas, las consecuencias, en esta vertiente hegemónica, ha provocado un vacío de contenido al valor de la responsabilidad. A día de hoy sólo somos capaces de captar su necesidad ante la incontestable realidad que ofrecen los efectos de una acción. Si no vemos las ondas expansivas, como de hecho ocurre en un economía de mercado global como la nuestra, la responsabilidad se diluye. Por eso, es importante reconocer la insuficiencia de las consecuencias en la esfera de un mercado global para comprender todo el alcance de la responsabilidad en él. El proceso de la responsabilidad arranca con las consecuencias, pero no finaliza con ellas, sino que prosigue hasta llegar al núcleo mismo del sistema que provoca que esas consecuencias sean unas u otras. La responsabilidad exige un salto cualitativo que sitúe a las organizaciones en relación con la sociedad. No fuera del sistema. Sino dentro de él. La falta de transparencia, la especulación, la tensión por la superrentabilidad, los incentivos millonarios para que los directivos impulsen crecimientos en sus entidades a cualquier precio, todos estos factores están conduciendo al colapso del sistema. La actual situación de crisis llama a plantear otro tipo de alternativas y otro modelo de responsabilidad distinto que vaya más allá de las medidas de control, vigilancia y supervisión con las que se pretende frenar su efecto a nivel planetario.

\section{OTRA CARTOGRAFÍA PARA LA RESPONSABILIDAD.}

La mayor debilidad del rostro de las consecuencias es que convierte a la empresa en una organización autista, incomunicada, alejada, ausente de la sociedad. La empresa se erige como la única legitimada para delimitar el contenido de su responsabilidad, para decidir ella sola, de manera unilateral, sobre aquello que es necesario responder, o atender; como si ella ciertamente estuviese sola, ajena a todo lo que acontece en torno a su actividad, y extraña a las relaciones con su entorno más inmediato, incluso aunque este entorno sea un entorno transnacional, o un entorno en red.

La atención a las particularidades del entorno y a la incidencia de las empresas en ese contexto pone de relieve, en última instancia, dos dinámicas de la responsabilidad claramente diferenciadas. Por un lado están las aproximaciones que como hemos visto enfatizan las consecuencias que tienen los impactos negativos o por omisión de las empresas. Estas son aproximaciones que se centran en las posibles imputaciones por aquello hecho o causado por las empresas en ese entorno. Y reclama, al igual que ahora lo hace también Obama, el papel normativo y controlador de los poderes públicos. Las empresas responden reactivamente con un discurso defensivo, en el que se intenta poner en valor lo mucho que el tejido empresarial aporta al bienestar de la sociedad y que debe ser puesto en una balanza en la que lo imputado pueda ser compensado por estos otros beneficios que redundan en la sociedad. Si la balanza sigue recayendo del lado de las imputaciones, la maniobra suele consistir en implicar al ciudadano de a pie en el proceso para, entre la multitud de ciudadanos mercantiles, consumidores, del mundo, repartir las costas del proceso por la falta de responsabilidad. 
Sobre la base de estos análisis, el desarrollo de metodologías, herramientas o indicadores tan gratos a la ingeniería de la responsabilidad, las políticas de promoción de la responsabilidad se orientan hacia la detección de debilidades estratégicas y la gestión de procesos de mejora orientados a anular o minimizar esas debilidades. "Lo hicimos con la calidad y el medioambiente, hagámoslo ahora con la responsabilidad social”, se escucha con frecuencia en los grupos de trabajo sobre esta cuestión.

Frente a los enunciados retrospectivos, aparece otra aproximación al entorno desde un enfoque prospectivo, que se relaciona con los conceptos de deber, previsión o cuidado, y que no conducen necesariamente a actitudes defensivas sino todo lo contrario: propicia una labor pública más proactiva y en coordinación con otros agentes, como, en este caso, pudieran ser las empresas, y a éstas últimas esta dinámica les orienta hacia el descubrimiento de nuevas oportunidades de situarse adecuadamente en el entorno social en el que están insertas.

Este enfoque que proponemos, una sociedad que mira a la empresa y la reconoce como responsable, sitúa, como decimos, el escenario de la RSE en otras coordenadas. Y además permite superar falsos debates como el de la voluntariedad u obligatoriedad de las empresas respecto a la responsabilidad. ¿Cómo de voluntario es comportarse responsablemente? ¿En qué medida es una cuestión que depende exclusivamente de la libre decisión de una organización responsable? ¿Puede quedar en manos de la estricta voluntad de la empresa contaminar más o menos, reconocer el derecho de las mujeres a las mismas condiciones laborales que los hombres, ofrecer empleo de calidad o establecer relaciones de mutuo beneficio con la comunidad? Seguramente no resulta posible (ni siquiera deseable) regular por ley determinados comportamientos, pero eso no quiere decir que puedan quedar al criterio parcial de una organización empresarial. Existen "obligaciones" sociales, formas de comportarse (o de no comportarse) que deben ser así, si queremos que nuestras sociedades sean lugares en las que todos queramos (y podamos) vivir.

Las estrategias de promoción de la responsabilidad social de la empresa impulsadas desde el ámbito público o autoasumidas por empresas y organizaciones deben afrontar esta clarificación conceptual como condición imprescindible para poder introducirse y arraigar en el tejido empresarial de forma generalizada. También es necesaria esta clarificación para que dichas estrategias sean entendidas por la sociedad como algo digno de confianza, y no como una nueva operación de maquillaje o reposicionamiento más propio de los departamentos de Marketing que de la Dirección Ejecutiva de la compañía. Sin esa clarificación, no será posible responder a la cuestión clave del para qué de muchas de las propuestas de avance de la responsabilidad.

Pero no sólo es necesaria la clarificación. Una vez desbrozado el camino, también es imprescindible optar por esa dinámica de la responsabilidad que mira al futuro, que impulsa a las empresas a cuidar la sociedad en los ámbitos en los que la empresa tiene poder y, por tanto, responsabilidad. Al hacer pivotar la estrategia de responsabilidad social en la dinámica prospectiva, se supera la dimensión estrictamente normativa propia de la mirada a lo ya hecho, que queda en el ámbito más propio de los mecanismos 
del derecho que se ocupan de la restitución por lo no cumplido o por el daño causado. Siendo imprescindible la vigilancia legal sobre la actividad empresarial, no es este el campo adecuado para el impulso de la responsabilidad social de la empresa.

La responsabilidad prospectiva hace cobrar relevancia a las intenciones futuras, al largo plazo. No nos movemos, de esta manera, en el terreno de lo estrictamente normativo, sino en el terreno en el que la condición de partida es la participación informada de la sociedad en la actuación de la empresa. Un terreno en el cobra importancia la adecuada interrelación entre todos los colectivos o grupos de interés que interaccionan en la actividad empresarial, en una dinámica de asunción de deberes y exigencia de derechos que consolida el desarrollo de los compromisos asumidos.

Por todo esto, nuestros tiempos exigen "ensanchar" la responsabilidad no tanto conceptualmente (lo que supondría su desvirtuación) como contextualmente, dando cuenta de la naturaleza de los distintos ámbitos e instancias nuevos a los que remite y que hacen más compleja su dinámica. Siendo esta una exigencia que no va exclusivamente dirigida al tejido empresarial, es necesario también afirmar que éste no puede quedar exento de ella. Los nuevos retos de la responsabilidad amplían el contexto en el que ésta se desarrolla, superando el ámbito de lo directamente causado, para introducirse en las preocupaciones por cuidar nuestras sociedades. El avance hacia sociedades más justas, el respeto a la dignidad de todas las personas o el desarrollo sostenible solo pueden presentar su sentido más plenificador en esta dirección de la dinámica de la responsabilidad entendida como cuidado.

Muchas veces se escuchan quejas por parte de responsables empresariales en el sentido de que "parece que con estas nuevas demandas se intenta convertir a las empresas en ONGs". Se argumenta que el bien social propio o intrínseco de la empresa se inscribe exclusivamente en la esfera de lo económico, que es donde deben dar cuenta de sus responsabilidades, que tienen que ver con la puesta a disposición de la sociedad de determinados productos o servicios. En esta simple dinámica, todo lo demás, incluida cualquier otra preocupación social más o menos justificada o urgente, es ajeno a la empresa que deberá, eso sí, evitar hacer un daño directo en el desarrollo de sus actividades. En todo caso, las empresas con mejores cuentas de resultados o una cierta disposición personal de sus directivos o propietarios hacia este tipo de demandas pueden responder con alguna iniciativa caritativa o paternalista que las acalle y, colateralmente, otorgue una posición de ventaja competitiva frente a otras empresas menos "responsables".

Quizás otros tiempos pudieron permitir parcializar tan radicalmente la responsabilidad. Nuestras sociedades globales, desiguales, interconectadas,... no. Los nuevos retos de esa responsabilidad prospectiva ampliada nos obligan a todos a cuidar la sociedad que todos componemos. Eso es la responsabilidad social. Cada ciudadano, cada institución educativa o turística o cultural, cada administración pública, cada empresa, debe trascender su contexto inmediato de actuación y mirar alrededor. Descentrase y asumir que nada le es ajeno.

Una empresa socialmente responsable deberá asumir compromisos ante el resto de la sociedad que respondan a un enfoque prospectivo y ampliado de su rol social. Y es 
bajo esta óptica bajo la que se debe evaluar la eficacia o adecuación de las distintas políticas, estrategias y herramientas para la promoción de la responsabilidad social que se propongan.

\section{REFERENCIAS:}

Cruz, C.; Sasia, P. y Guibert, J.M. (2007): “La responsabilidad social en Gipuzkoa ¿por dónde empezar?”, en Guibert. J.M. (coord.) Empresa y Responsabilidad Social en Gipuzkoa. San Sebastián: Universidad de Deusto, pp.23-40.

Cruz, M. y Aramayo, R. R. (Coord.) (1999): El reparto de la acción. Ensayos en torno a la responsabilidad. Madrid: Trotta.

Jonas, H. (1994): El Principio de Responsabilidad. (Ensayo de una ética para la civilización tecnológica). Barcelona: Herder.

Sasia, P. (2004): La Empresa a Contracorriente. Cuestiones de ética empresarial. Bilbao: Mensajero.

Sasia, P. y de la Cruz, C. (2008): Banca ética y ciudadanía. Madrid: Trotta. 